\title{
Single-step genomic evaluation of milk production traits in Canadian Alpine and Saanen dairy goats
}

\author{
Erin Massender, ${ }^{1 *} \odot$ Luiz F. Brito, ${ }^{1,2} \odot$ Laurence Maignel, ${ }^{3} \odot$ Hinayah R. Oliveira, ${ }^{1,2} \odot$ Mohsen Jafarikia, ${ }^{1,3} \odot$ \\ Christine F. Baes, ${ }^{1,4}{ }^{\circ}$ Brian Sullivan, ${ }^{3} \odot$ and Flavio S. Schenkel ${ }^{1} \odot$ \\ ${ }^{1}$ Centre for Genetic Improvement of Livestock, Department of Animal Biosciences, University of Guelph, Guelph, ON, Canada, N1G 2W1 \\ ${ }^{2}$ Department of Animal Sciences, Purdue University, West Lafayette, IN 47907 \\ ${ }^{3}$ Canadian Centre for Swine Improvement Inc., Ottawa, ON, Canada, K1A 0C6 \\ ${ }^{4}$ Institute of Genetics, Vetsuisse Faculty, University of Bern, 3001 Bern, Switzerland
}

\section{ABSTRACT}

Genomic evaluations are routine in most plant and livestock breeding programs but are used infrequently in dairy goat breeding schemes. In this context, the purpose of this study was to investigate the use of the single-step genomic BLUP method for predicting genomic breeding values for milk production traits (milk, protein, and fat yields; protein and fat percentages) in Canadian Alpine and Saanen dairy goats. There were 6,409 and 12,236 Alpine records and 3,434 and 5,008 Saanen records for each trait in first and later lactations, respectively, and a total of 1,707 genotyped animals (833 Alpine and 874 Saanen). Two validation approaches were used, forward validation (i.e., animals born after 2013 with an average estimated breeding value accuracy from the full data set $\geq 0.50)$ and forward cross-validation (i.e., subsets of all animals included in the forward validation were used in successive replications). The forward cross-validation approach resulted in similar validation accuracies ( 0.55 to 0.66 versus 0.54 to 0.61$)$ and biases ( -0.01 to -0.07 versus -0.03 to 0.11 ) to the forward validation when averaged across traits. Additionally, both single and multiple-breed analyses were compared, and similar average accuracies and biases were observed across traits. However, there was a small gain in accuracy from the use of multiple-breed models for the Saanen breed. A small gain in validation accuracy for genomically enhanced estimated breeding values (GEBV) relative to pedigreebased estimated breeding values (EBV) was observed across traits for the Alpine breed, but not for the Saanen breed, possibly due to limitations in the validation design, heritability of the traits evaluated, and size of the training populations. Trait-specific gains in theoretical accuracy of GEBV relative to EBV for the vali-

Received April 1, 2021.

Accepted November 9, 2021.

*Corresponding author: emassend@uoguelph.ca dation animals ranged from 17 to $31 \%$ in Alpine and 35 to $55 \%$ in Saanen, using the cross-validation approach. The GEBV predicted from the full data set were 12 to $16 \%$ more accurate than EBV for genotyped animals, but no gains were observed for nongenotyped animals. The largest gains were found for does without lactation records (35-41\%) and bucks without daughter records (46-54\%), and consequently, the implementation of genomic selection in the Canadian dairy goat population would be expected to increase selection accuracy for young breeding candidates. Overall, this study represents the first step toward implementation of genomic selection in Canadian dairy goat populations.

Key words: dairy goat, genomic selection, milk production trait, single-step genomic prediction, singlestep genomic best linear unbiased prediction

\section{INTRODUCTION}

The demand for goat cheese and other products derived from goat milk continues to grow in Canada and around the world. Although domestic goat milk production approximately doubled between 2008 and 2018 (32.5 to 62.2 million liters), about $108,000 \mathrm{~kg}$ of goat cheese was imported into Canada in 2019 (Canadian Dairy Information Centre, 2019). This suggests that an opportunity remains for the expansion of Canadian dairy goat production to meet domestic demand. However, the current global focus on sustainable livestock production favors increasing production efficiency, rather than continuing to expand the national goat herd (Brito et al., 2021; Statistics Canada, 2020). Furthermore, improving the efficiency and profitability of goat milk production is crucial to the competitiveness of the Canadian dairy goat industry relative to international competitors.

Genetic selection is one proven method of increasing the efficiency of livestock production (e.g., Miglior et al., 2017) that has been traditionally underutilized in the Canadian dairy goat industry. Genetic evaluations 
for milk production and conformation traits are provided to enrolled Canadian dairy goat producers by the Canadian Centre for Swine Improvement through the Canadian Dairy Goat Genetic Improvement Program (www.goatgenetics.ca). The 5 milk production traits that are currently evaluated are milk yield (MY), protein yield $(\mathbf{P Y})$, fat yield $(\mathbf{F Y})$, protein percentage $(\mathbf{P P})$, and fat percentage (FP). Genetic evaluations for these traits are performed across lactations using single-trait random regression models and expressed as a total kilogram (MY, FY, PY) or percentage (FP, $\mathrm{PP}$ ) deviation from the breed-average over a standard 305-d lactation (Sullivan, 2000). The traits evaluated and methodologies used in the Canadian Dairy Goat Genetic Improvement Program have remained largely unchanged since its inception and could be enhanced by taking advantage of progress in animal breeding methods that have been successfully implemented in other livestock species and countries.

Genomic selection is one innovation that has revolutionized livestock breeding programs around the world (e.g., Van Eenennaam et al., 2014; Georges et al., 2019). The use of genomic information has been shown to substantially increase the rate of genetic gain in many livestock industries, including the Canadian dairy cattle industry, where rates of annual genetic gain have more than doubled, especially for lowly-heritable traits (Beavers and Van Doormaal, 2017; Miglior et al., 2017; Brito et al., 2021). The accelerated rate of genetic gain through the use of genomic selection is achieved by reducing generation intervals and increasing accuracy and intensity of selection (Schaeffer, 2006; Van Eenennaam et al., 2014; García-Ruiz et al., 2016). Incorporation of genomic information has also enabled selection for numerous traits that are difficult or expensive to measure in various industries (e.g., health and disease resistance, feed efficiency, carcass and meat quality) that were previously impractical to include in pedigreebased genetic evaluation programs (e.g., Daetwyler et al., 2012; Chesnais et al., 2016; Brito et al., 2017a).

Many different methodologies for the prediction of genomically enhanced estimated breeding values (GEBV) have been investigated. For instance, VanRaden (2008) proposed the genomic BLUP (GBLUP) method for the prediction of GEBV in dairy cattle. However, the single-step GBLUP (ssGBLUP) method, as proposed by Misztal et al. (2009) and Christensen and Lund (2010), has become the most popular for small ruminant genomic evaluations where genomic training population sizes are relatively small due to the limited number of individuals with both genotypes and phenotypes (Rupp et al., 2016). In addition, ssGBLUP is often simpler to implement compared with GBLUP, reduces the loss of information that may occur through multiple-step methods, and provides GEBV for all animals included in the pedigree (Aguilar et al., 2010; Legarra et al., 2014). The ssGBLUP approach replaces the pedigreebased relationship matrix (A) of traditional BLUP evaluations with a hybrid matrix $(\mathbf{H})$ that accounts for realized relationships using both pedigree and genomic information (Legarra et al., 2009; Misztal et al., 2009). There are several parameters (called blending and scaling factors) that may influence the accuracy and bias of single-step GEBV (Lourenco et al., 2020). The values used for these parameters are population-specific and they need to be defined to optimize the prediction of GEBV (i.e., maximize validation accuracy while reducing bias), especially when inbreeding is not accounted for in the analyses (Tsuruta et al., 2019).

Compared with dairy cattle, the benefits of genomic selection may be lower for small ruminants (van der Werf, 2009; Shumbusho et al., 2013; Rupp et al., 2016; Shumbusho et al., 2016). Factors limiting the benefits of genomic selection in small ruminants include their shorter generation interval, the use of many different breeds, greater within-breed genetic diversity (Brito et al., 2015, 2017b), limited use of AI, the high cost of genotyping relative to the value of the animal, and the industry coordination and expense required to develop large training populations. The cost for genotyping at the time of this study was approximately $\$ 100$ per sample. Although the costs have declined in recent years to approximately $\$ 30$ to 40 per sample, participation in genomic selection programs continues to require a significant investment. Routine genotyping of dairy goats is currently cost prohibitive, but it may be possible in the future for commercial herds that have not traditionally participated in pedigree-recording schemes to receive genomic evaluations, which would increase the number of phenotypes and the connectedness of herds within the population. Research aimed at the implementation of genomic selection in dairy goats is a current area of study in several countries including France, the United Kingdom, and Canada.

Previous research by Brito et al. (2015, 2017b) evaluated genetic diversity and the extent of linkage disequilibrium in Canadian dairy goat breeds and concluded that genomic selection is likely feasible if training population sizes are sufficiently large. Small gains to validation accuracy were observed for GEBV predicted for a small population of 367 Canadian Alpine goats using a multiple-step method (Vermette et al., 2013). The size of training populations is a limitation to the accuracy of genomic breeding values (e.g., Hayes et al., 2009; Goddard, 2012), and pooling of breeds is often a strategy for small ruminant populations with limited genotyping (e.g., Carillier et al., 2014; Brito et al., 2017a). However, Brito et al. (2015) reported that 
the consistency of gametic phase is not high enough between Canadian dairy goat breeds to encourage the use of multiple-breed genomic training populations, contrary to the results of Carillier et al. (2014) for French Alpine and Saanen goats.

In this context, the objectives of this study were to (1) compare the use of single- and multiple-breed training populations in a ssGBLUP approach for predicting milk production trait GEBV; and (2) assess the effect of incorporating genomic information on the accuracy and bias of genetic evaluations for Canadian Alpine and Saanen goat breeds.

\section{MATERIALS AND METHODS}

\section{Data}

Data used in this research were obtained from industry organization records or samples collected by commercial producers; thus, institutional animal care approval was not required. Milk production phenotypes were provided by the Canadian Centre for Swine Improvement (www.ccsi.ca) through the Dairy Goat Genetic Improvement Program. Only data from the Alpine and Saanen breeds were included in this study, as they are the most prevalent dairy goat breeds in Canada and worldwide, and they were the focus of genotyping efforts. The data included MY, FY, and PY (kg) as well as PP and FP (\%). The full lactation milk production phenotypes were estimated for all does with lactations of at least $150 \mathrm{~d}$ in length with the routine test-day genetic evaluation models used in the Canadian Dairy Goat Genetic Improvement Program (Sullivan, 2000).

The phenotypic data were separated by breed and lactation, with first-lactation traits, which are denoted throughout the text with the number 1 (i.e., MY1), considered separately from later lactation traits (i.e., MY2+). First and later lactation records were analyzed separately as the genetic correlation between first- and later-parity traits was considerably less than one in preliminary tests, violating a key assumption of repeated records animal models. Phenotypic quality control was performed to remove duplicate or incomplete records and contemporary groups with only 1 animal, using the $\mathrm{R}$ software version 3.6.3 (https://www.r-project .org/). The final data sets included 6,409 and 12,236 Alpine records and 3,434 and 5,008 Saanen records, for first and later lactations, respectively. The number of phenotypic records (Table 1) and number of does with records (Table 2) were substantially greater for the Alpine breed, but slightly more genotypes were available for the Saanen animals (Table 2). There were some differences in the phenotypic means, ranges, and variation between breeds and parities (Table 1). The later-parity data sets contained records from lactations 2 to 11 . The later lactation data set for the Alpine breed contained $41 \%, 27 \%, 16 \%$, and $16 \%$ of records in lactations 2,3 , 4 , or $5+$, respectively, whereas the Saanen data set contained $46 \%, 26 \%, 15 \%$, and $13 \%$ of records in the same categories. The single-breed data sets were combined for the multiple-breed analyses.

Table 1. Descriptive statistics for the population by breed and trait ${ }^{1}$

\begin{tabular}{llcccr}
\hline Breed & Trait & $\mathrm{N}^{2}$ & Mean $\pm \mathrm{SD}$ & Range & CV $(\%)$ \\
\hline Alpine & MY1 & 6,409 & $793.4 \pm 249.5$ & $102.0-2,003.0$ & 31.4 \\
& PY1 & 6,409 & $24.7 \pm 7.8$ & $3.0-65.0$ & 31.6 \\
& FY1 & 6,409 & $27.9 \pm 10.8$ & $3.0-113.0$ & 38.5 \\
& PP1 & 6,409 & $3.1 \pm 0.3$ & $1.4-5.5$ & 8.6 \\
FP1 & 6,409 & $3.5 \pm 0.6$ & $1.6-8.9$ & 18.1 \\
MY2 & 12,236 & $879.0 \pm 288.5$ & $156.0-2,309.0$ & 32.8 \\
& PY2+ & 12,236 & $26.9 \pm 8.9$ & $5.0-69.0$ & 32.9 \\
FY2+ & 12,236 & $29.5 \pm 11.3$ & $5.0-119.0$ & 38.4 \\
& PP2+ & 12,236 & $3.1 \pm 0.3$ & $2.0-4.6$ & 8.4 \\
& FP2+ & 12,236 & $3.3 \pm 0.5$ & $1.4-9.9$ & 16.3 \\
& MY1 & 3,434 & $921.0 \pm 361.5$ & $197-2,971$ & 39.2 \\
& PY1 & 3,434 & $28.6 \pm 11.3$ & $5.0-83.0$ & 39.4 \\
& FY1 & 3,434 & $32.9 \pm 14.6$ & $5.0-113.0$ & 44.3 \\
& PP1 & 3,434 & $3.1 \pm 0.3$ & $2.2-6.1$ & 8.7 \\
& FP1 & 3,434 & $3.6 \pm 0.7$ & $1.8-10.4$ & 19.2 \\
& MY2 & 5,008 & $1,015.4 \pm 441.7$ & $138.0-3,688.0$ & 43.5 \\
& PY2+ & 5,008 & $30.7 \pm 13.2$ & $4.0-107.0$ & 42.9 \\
& FY2 + & 5,008 & $34.2 \pm 16.1$ & $4.0-119.0$ & 47.2 \\
& PP2+ & 5,008 & $3.1 \pm 0.3$ & $1.9-4.4$ & 8.6 \\
& FP2 + & 5,008 & $3.4 \pm 0.6$ & $1.1-9.0$ & 18.0 \\
\hline
\end{tabular}

${ }^{1}$ Phenotypes used in this study were full lactation records for milk yield (MY; $\mathrm{kg}$ ), protein yield (PY; $\mathrm{kg}$ ), fat yield (FY; kg), protein percentage (PP; \%), and fat percentage (FP; \%). The codes 1 and $2+$ after the trait abbreviations refer to first and later lactations, respectively.

${ }^{2} \mathrm{~N}=$ number of records. 
Table 2. Number of animals with phenotypes, genotypes, and both genotypes and phenotypes; their average pedigree depth; and number (\%) of animals with known sires and dams, by breed and lactation

\begin{tabular}{|c|c|c|c|c|}
\hline \multirow[b]{2}{*}{ Item } & \multicolumn{2}{|c|}{ Alpine } & \multicolumn{2}{|c|}{ Saanen } \\
\hline & First lactation & Later lactations & First lactation & Later lactations \\
\hline Animals with phenotypes & 6,409 & 5,827 & 3,434 & 2,632 \\
\hline Average pedigree depth & 16.7 & 15.8 & 18.4 & 18.2 \\
\hline Known sires & $570(98 \%)$ & $635(98 \%)$ & $375(93 \%)$ & $380(94 \%)$ \\
\hline Known dams & $3,533(88 \%)$ & $3,382(89 \%)$ & $1,863(85 \%)$ & $1,498(86 \%)$ \\
\hline Animals with genotypes & 833 & 833 & 874 & 874 \\
\hline Average pedigree depth & 17.8 & 17.8 & 20.3 & 20.3 \\
\hline Known sires & $226(98 \%)$ & $226(98 \%)$ & $202(96 \%)$ & $202(96 \%)$ \\
\hline Known dams & $639(97 \%)$ & $639(97 \%)$ & $586(96 \%)$ & $586(96 \%)$ \\
\hline Animals with both & 552 & 589 & 601 & 542 \\
\hline Average pedigree depth & 18.4 & 18 & 20.9 & 20.3 \\
\hline Known sires & $133(99 \%)$ & $151(99 \%)$ & $131(98 \%)$ & $137(97 \%)$ \\
\hline Known dams & $453(99 \%)$ & $473(99 \%)$ & $432(98 \%)$ & $387(96 \%)$ \\
\hline
\end{tabular}

\section{Pedigree}

Pedigree information for registered animals obtained from the Canadian Livestock Records Corporation (www.clrc.ca) was trimmed to only include ancestors of animals with records or genotypes, and a pedigree analysis was performed with the pedigree package (Coster, 2013) in the $\mathrm{R}$ software version 3.6.3. The pedigrees for Alpine and Saanen had 13,437 and 7,379 animals, respectively, whereas the multiple-breed pedigree had 20,239 animals. It is worth noting that only a small number of ancestors were shared between the pedigrees of both breeds, as demonstrated by the relative sizes of the single and multiple-breed pedigrees. Average pedigree depth was similar between breeds and parities; does with records had an average pedigree depth of 15.8 to 18.4 generations, whereas animals with genotypes had an average pedigree depth of 17.8 to 20.3 generations (Table 2). Sire and dam information was known for most genotyped animals and does with phenotypic records, with the Saanen breed having a lower percentage of known parents than Alpine (Table 2). The seekparentf90 program (Misztal et al., 2014) was used to identify and correct pedigree errors found in 59 genotyped parent-progeny pairs by first searching for matching animals among all genotyped, followed by setting the parent with a conflict to missing (43 animals) if a match was not found. Increasing pedigree completeness and correcting errors is an additional benefit of increasing the number of genotyped animals in the population, which would be expected to improve the accuracy of genetic evaluations.

\section{Genotypes}

There were 1,707 genotyped animals, of which 833 were from the Alpine breed (78 bucks, 755 does) and 874 were from the Saanen breed (97 bucks, 777 does), as shown in Supplemental Table S1 (https://doi.org/ 10.7910/DVN/AXUQDT). The genotypes were obtained from various sample types (blood, nasal swab, tissue, and semen) collected during 2 separate projects by commercial producers and industry organizations. A total of 720 samples were collected between 2011 and 2013 in a previous project (Vermette et al., 2013), and 987 samples were collected between 2017 and 2019 as part of the present project. Herds with registered Alpine or Saanen goats across Canada were recruited to provide samples for genotyping. Where possible, animals were selected based on the available phenotypic information, with preference for genotyping given to does enrolled in milk-recording (305 d or $1 \mathrm{~d}$ ) and bucks with daughter records, as these animals would be expected to have the most benefit to the creation of a genomic training population. Tissue samples were obtained from over 24 herds, AI centers, or research institutions from animals born between 1993 and 2019 (Supplemental Table S1). The tissue samples collected in the present project were genotyped by NeoGen Canada with version 1 of the GoatSNP50 Bead Chip (Tosser-Klopp et al., 2014) from Illumina Inc. that contains 53,347 SNP.

Genotypic quality control was performed separately for each breed for use in the single-breed analyses and across all genotypes for the multiple-breed analyses, using the preGSf90 software (Aguilar et al., 2014; Misztal et al., 2014). The SNP from autosomal chromosomes of all animals genotyped with a call rate of at least 0.90 were retained. The SNP with Mendelian conflicts, call rates less than 0.90 , and minor allele frequencies less than 0.05 or with heterozygosity deviating from Hardy-Weinberg Equilibrium expectations $(>0.15)$ were excluded. The quality control procedures retained $45,221(84.8 \%)$ SNP for the multiple-breed data set, and 44,598 (83.6\%) and 43,598 (81.7\%) SNP for Alpine and Saanen, respectively. 
After genotype quality control, a principal component analysis (PCA) of the genomic relationship matrix was performed to evaluate the stratification of the genotyped animals by breed, herd, and assignment to the genomic training or validation populations. The PCA was performed with tidyverse packages (Wickham et al., 2019) and $\mathrm{R}$ version 3.6.3.

\section{Statistical Analyses}

Genetic parameters and breeding values were analyzed with univariate models, with first and later lactation records analyzed separately for each trait, using the airemlf90 and blupf90 programs (Misztal et al., 2002). The genetic parameters were estimated using all available genomic and pedigree data (i.e., based on the ssGBLUP method). The effects included in the models were similar to those used in routine genetic evaluations for Canadian dairy goats (Sullivan, 2000) and included fixed effects of breed (Alpine or Saanen), doe age (in months, 8 to $108+$ ), as well as parity (2 to $7+$ ) in the models for later lactation traits, and a covariate of days in milk at the final milk test for the lactation. The random effects included contemporary group, based on herd and year of test, animal additive genetic effect, as well as permanent environmental effects in the models for later lactation traits. For the multiple-breed analyses, the phenotypes recorded on Alpine and Saanen were considered a single-trait with a pooled training population. The animal models used for the first-lactation traits are defined as follows:

$$
\mathbf{y}=\mathbf{X} \mathbf{b}+\mathbf{Z}_{u} \mathbf{u}+\mathbf{Z}_{w} \mathbf{w}+\mathbf{e},
$$

where $\mathbf{y}$ is a vector of phenotypes for the $i$ th trait, $\mathbf{b}$ is a vector of fixed effects for the analyzed trait (i.e., MY1, PY1, FY1, PP1, FP1), $\mathbf{u}$ is a vector of random animal additive genetic effects, $\mathbf{w}$ is a vector of random contemporary group effects, and $\mathbf{e}$ is a vector of random residual effects. $\mathbf{X}, \mathbf{Z}_{w}$, and $\mathbf{Z}_{w}$ are the design matrices relating observations to fixed, animal additive genetic, and contemporary group effects, respectively. It was assumed that the animal additive genetic effects were normally distributed with a mean of zero and a variance $\mathbf{H} \sigma_{u}^{2}$, where $\mathbf{H}$ is a realized relationship matrix combining both pedigree and genomic information (Legarra et al., 2009) and $\sigma_{u}^{2}$ is the estimated animal additive genetic variance. The random contemporary group and residual effects were assumed to be normally distributed with a mean of zero and variance $\mathbf{I} \sigma_{w}^{2}$ and $\mathbf{I} \sigma_{e}^{2}$, respectively, where $\mathbf{I}$ is an identity matrix and $\sigma_{w}^{2}$ and $\sigma_{e}^{2}$ are the estimated contemporary group and residual variances, respectively. The inverse of $\mathbf{H}$ was calculated as follows:

$$
\mathbf{H}^{-1}=\mathbf{A}^{-1}+\left[\begin{array}{cc}
0 & 0 \\
0 & \tau\left(\alpha \mathbf{G}-\beta \mathbf{A}_{22}\right)^{-1}-\omega \mathbf{A}_{22}{ }^{-1}
\end{array}\right],
$$

where $\mathbf{A}^{-1}$ is the inverse of the pedigree-based relationship matrix, created using all available pedigree and accounting for inbreeding, $\mathbf{G}$ is the genomic relationship matrix calculated using the first method presented in VanRaden (2008) and allele frequencies that were estimated from the genotypes, and $\mathbf{A}_{22}$ is the section of $\mathbf{A}$ related to genotyped animals. Blending factors $\alpha$ and $\beta$ were used to make $\mathbf{G}$ invertible and account for polygenic effects, whereas the $\tau$ and $\omega$ parameters (i.e., scaling factors) were used to account for reduced genetic variance and different pedigree depths, respectively, to make $\mathbf{G}$ compatible with $\mathbf{A}_{22}$.

The optimal combination of blending and scaling parameters was defined based on average validation accuracies and biases across all traits and breeds (see details in the "Validation Accuracy and Bias" section). For the blending factors, 3 values of $\alpha(0.90,0.95,0.99)$ were tested, with corresponding $\beta=(1-\alpha)$ values. For the scaling factors, 4 different values were tested for $\tau$ $(0.5,1.0,1.5,2.0)$ and 6 values were tested for $\omega(0.5$, $0.6,0.7,0.8,0.9,1.0)$, based on typical scenarios tested in dairy cattle literature (e.g., Oliveira et al., 2019). The blending parameters had minimal effect on validation accuracy or bias; therefore, the default parameters ( $\alpha=0.95$ and $\beta=0.05$ ) were used. The optimal scaling parameters were found to be $\tau=1.0$ and $\omega=0.8$.

A repeated records model was used to analyze laterparity phenotypes, which is defined as follows:

$$
\mathbf{y}=\mathbf{X} \mathbf{b}+\mathbf{Z}_{u} \mathbf{u}+\mathbf{Z}_{w} \mathbf{w}+\mathbf{Z}_{p} \mathbf{p}+\mathbf{e},
$$

where $\mathbf{p}$ is a vector of permanent environmental effects, $\mathbf{Z}_{p}$ is a design matrix relating observations to permanent environmental effects, and all other effects are as previously described. It was assumed that the permanent environmental effects were normally distributed with a mean of zero and a variance $\mathbf{I} \sigma_{p e}^{2}$, where $\mathbf{I}$ is an identity matrix of animals with records, $\sigma_{p e}^{2}$ is the estimated permanent environmental variance, and expectations and variances for the other random effects were as previously described for the first-lactation traits. The same blending and scaling factors previously described were also tested to compute the $\mathbf{H}$ inverse for the later lactation traits.

\section{Training and Validation Populations}

The genotyped animals were divided into training and validation populations by year of birth and the theoretical accuracy of their pedigree-based EBV esti- 
mated using all available phenotypes (EBV_full) in the multiple-breed analyses. Animals born after 2013 with an average EBV_full theoretical accuracy $\geq 0.50$ across traits within each lactation were deemed eligible for inclusion in the validation population. The EBV and GEBV predicted from the full data sets were used as an approximation of the animal's true breeding value in the validation analyses. Thus, this accuracy threshold was set to ensure that only animals with reliable breeding values were used as benchmarks in the validation analyses. All genotyped animals not selected as validation animals in a given scenario were retained as part of the training population, regardless of their year of birth. In total, 231 and 227 Alpine goats and 234 and 217 Saanen goats were eligible for the validation populations for first and later lactation traits, respectively.

Two strategies were used to define validation populations as follows: (1) forward validation and (2) forward cross-validation. For the forward validation approach, all eligible animals (i.e., animals born after 2013 with an average $E B V \_f u l l$ accuracy $\geq 0.50$ ) were included in the validation population for each trait and lactation. Whereas, for the forward cross-validation approach, 10 random subsets of 100 animals were selected from the eligible animals, and the validation analyses were repeated with results averaged over the 10 replicates. This strategy was used to maximize the number of animals with genotypes and phenotypes in the training population, given the limited number of genotyped animals. After, animals were assigned to either training or validation populations for each scenario (i.e., single or multiple-breed), and reduced data sets (EBV_val and GEBV_val) were created by removing all phenotypes of validation animals and their descendants. Thereafter, GEBV and EBV were predicted using both full and reduced data sets. For the traditional BLUP analyses, the $\mathbf{H}$ matrices described in the models above were replaced by $\mathbf{A}$. The validation and theoretical accuracy analyses hereafter described were all performed with tidyverse packages (Wickham et al., 2019) and the $\mathrm{R}$ software version 3.6.3.

\section{Validation Accuracy and Bias}

Validation analyses were performed to compare the average accuracies and biases of GEBV and EBV. Validation accuracy (VAL_ACC) was calculated based on the method proposed by Legarra and Reverter (2018) for the validation animals in each scenario (Eq. 1) as follows:

$$
\mathrm{VAL}_{-} \mathrm{ACC}_{i}=\sqrt{\frac{\operatorname{cov}\left((\mathrm{G}) \mathrm{EBV}_{\text {ifull }},(\mathrm{G}) \mathrm{EBV}_{\text {ival }}\right)}{(1-\overline{\mathrm{F}}) \sigma_{\mathrm{u} i}^{2}}},
$$

where the covariance between EBV or GEBV analyzed with full, (G)EBV $\mathrm{EFull}_{\text {, }}$ and reduced, (G)EB$\mathrm{V}_{\text {ireduced, }}$, data sets for the $i$ th trait were calculated, $\overline{\mathrm{F}}$ is the average inbreeding coefficient for animals in the validation population within each scenario, and $\sigma_{u i}^{2}$ is the estimated additive genetic variance for the $i$ th trait. Bias, defined as the inflation or deflation of breeding values computed from reduced data sets relative to full data sets, was calculated as the regression coefficient $\left(b_{1}\right)$ of the regression of GEBV_full or EBV_full on GEBV_val or EBV_val [i.e., (G)EBV full $\left.=b_{0}+b_{1}(\mathrm{G}) \mathrm{EBV}_{\text {val }}\right]$, respectively, minus 1 . For the forward cross-validation approach, average validation accuracies and biases and their corresponding standard deviations were calculated from across the 10 replicates.

\section{Theoretical Accuracy}

Average theoretical EBV and GEBV accuracies from reduced and full data sets were estimated to quantify the amount of information gained from the inclusion of genomic information. Theoretical accuracies (THE_ ACC) for breeding values of individual animals were calculated from standard errors of prediction, obtained from the blupf90 software, using the formula (Eq. 2) proposed by Van Vleck (1993):

$$
\mathrm{THE}_{-} \mathrm{ACC}_{i, j}=\sqrt{1-\frac{\left(s_{i, j}\right)^{2}}{\left(1+f_{j}\right) \sigma_{u, i}^{2}}},
$$

where THE_ACC ${ }_{i, j}$ is the estimated theoretical accuracy for the $i$ th trait EBV of the $j$ th animal, $f_{j}$ is the inbreeding coefficient for the $j$ th animal, $\sigma_{u, i}^{2}$ is the estimated additive genetic variance for the $i$ th trait and $s_{i, j}$ is the standard error of prediction for the $i$ th trait EBV of the jth animal. It should be noted that this method of calculating accuracy ignores selection-induced linkage disequilibrium (Bijma, 2012), but was a reasonable approximation for the purpose of comparing methodologies in this study.

After theoretical accuracies were calculated for all animals in both pedigree and genomic-based scenarios, the population was divided into various categories (e.g., validation animals, does with or without records, bucks with or without daughter records), and average theoretical accuracies within these subsets were calculated using the full data sets to assess the gain in accuracy from the inclusion of genomic information. Results are presented by trait for validation animals and as an average within each lactation for other subsets. 


\section{RESULTS AND DISCUSSION}

\section{Principal Component Analysis}

The first and second principal components of the genomic relationship matrix are presented in Figure 1, colored by breed and shaded by whether the animal was part of the training or validation population. The 2 breeds predominantly clustered separately, with the Saanen breed clustering less tightly than Alpine, suggesting greater variation in the Saanen breed. Although the genotyped population in the present study is larger and includes a greater number of herds, the PCA results were similar to those presented by Brito et al. (2015). Herds tended to cluster together (Supplemental Figure S1, https://doi.org/10.7910/DVN/GRW9BZ), which was expected, given that many purebred Canadian goat producers have closed herds. Animals selected for the validation population were dispersed well among the herds contributing genotypes to this study.

\section{Genetic Parameters}

Heritability estimates for the milk production traits studied were variable (Table 3 ), with estimates ranging from $0.09 \pm 0.02(\mathrm{SE})$ for MY2+ in Saanen to 0.56 \pm 0.02 for PP2+ in Alpine. Sullivan (2000) reported multiple-breed and parity heritability estimates from the test-day models used in the Canadian Dairy Goat Genetic Improvement Program to be 0.29, 0.30, and 0.27 for MY, PY, and FY, respectively. Carillier et al.
(2014) reported single-breed heritability estimates for the French dairy goat population across multiple-lactations of $0.31,0.31,0.28,0.60$, and 0.48 for Alpine and $0.26,0.25,0.25,0.56$, and 0.51 for Saanen for MY, PY, FY, PP, and FP, respectively, with all standard errors less than 0.02. Similar estimates were also reported by Teissier et al. (2019) for the same French population. Mucha et al. (2014) reported heritability estimates for MY in first and later lactations ranging from $0.23 \pm$ 0.03 to $0.45 \pm 0.02$ and $0.10 \pm 0.04$ to $0.34 \pm 0.02$, respectively, across lactations (4-400 DIM) using a random regression model for a UK composite dairy goat population developed by crossing Saanen, Alpine, and Toggenburg animals. In the same population, Mucha et al. (2018) reported heritability estimates of 0.29 for PY and 0.31 for FY. The heritability estimates observed in this research for the single-breed analyses of Saanen are on the low end of literature estimates, which may be because first and later lactation phenotypes were considered to be separate traits. Where the heritability estimates differed between breeds, the multiple-breed estimates were generally intermediary.

\section{Validation Analyses}

Validation Accuracy. The validation accuracies observed were moderately high (e.g., averaging 0.66 \pm 0.03 for Alpine and $0.55 \pm 0.03$ for Saanen using forward cross-validation and single-breed analyses; Table 4). One factor contributing to the relatively high validation accuracies, despite the small genomic

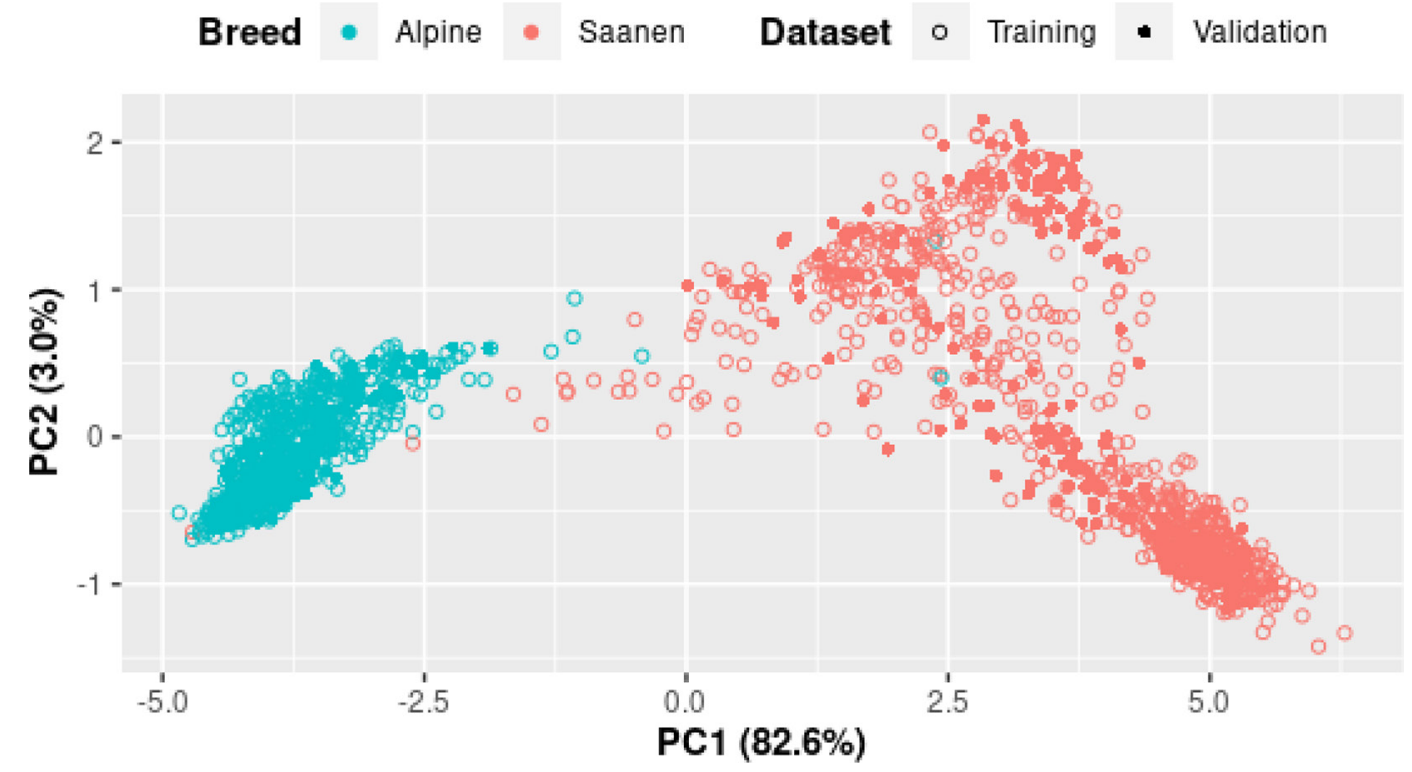

Figure 1. First and second principal components (PC) of the genomic relationship matrix, colored by breed and shaded by whether the animal was part of the training (open symbols) or validation (solid symbols) population. 
Table 3. Heritabilities $\left(\mathrm{h}^{2} \pm \mathrm{SE}\right)$ estimated for Alpine, Saanen, and both Alpine and Saanen combined ${ }^{1}$

\begin{tabular}{lccc}
\hline & \multicolumn{3}{c}{ Breed } \\
\cline { 2 - 4 } Trait & Alpine & Saanen & Alpine and Saanen \\
\hline MY1 & $0.26 \pm 0.02$ & $0.13 \pm 0.02$ & $0.19 \pm 0.02$ \\
PY1 & $0.24 \pm 0.02$ & $0.14 \pm 0.02$ & $0.18 \pm 0.02$ \\
FY1 & $0.24 \pm 0.02$ & $0.19 \pm 0.03$ & $0.22 \pm 0.02$ \\
PP1 & $0.46 \pm 0.03$ & $0.36 \pm 0.04$ & $0.41 \pm 0.02$ \\
FP1 & $0.27 \pm 0.03$ & $0.33 \pm 0.04$ & $0.31 \pm 0.02$ \\
MY2+ & $0.26 \pm 0.02$ & $0.09 \pm 0.02$ & $0.16 \pm 0.01$ \\
PY2+ & $0.27 \pm 0.02$ & $0.10 \pm 0.02$ & $0.16 \pm 0.01$ \\
FY2+ & $0.23 \pm 0.02$ & $0.14 \pm 0.02$ & $0.18 \pm 0.01$ \\
PP2+ & $0.56 \pm 0.02$ & $0.48 \pm 0.03$ & $0.54 \pm 0.02$ \\
FP2 & $0.42 \pm 0.02$ & $0.37 \pm 0.03$ & $0.42 \pm 0.02$ \\
\hline
\end{tabular}

${ }^{1}$ Phenotypes used in this study were full lactation records for milk yield (MY; $\mathrm{kg}$ ), protein yield (PY; kg), fat yield ( $\mathrm{FY}$; $\mathrm{kg}$ ), protein percentage (PP; \%), and fat percentage (FP; \%). The codes 1 and $2+$ after the trait abbreviations refer to first and later lactations, respectively. Genetic parameters were estimated with the single-step method with default parameters.

training populations, was the dispersion of validation animals across genotyped herds because the relatedness between training and validation population has an influence on the accuracy of genomic predictions (Clark et al., 2012). Validation accuracies for the majority of traits were found to be higher for the Alpine breed than the Saanen breed (Table 4). Given that more phenotypes were available for the Alpine breed, this finding highlights a key advantage of ssGBLUP, the ability to incorporate all available information for the prediction of GEBV (Legarra et al., 2014).

Carillier et al. (2014) reported lower multiple-breed validation accuracies, calculated as the Pearson correlation between buck daughter yield deviations and singlestep GEBV for MY (0.43), PY (0.33), FY (0.44), PP (0.70), and FP (0.61) when considering both breeds. Interestingly, Carillier et al. (2014) did not observe the same trend between breeds; rather, they found that GEBV validation accuracies were higher for Saanen than Alpine for most traits, even though more Alpine records and genotypes were analyzed, and heritability estimates were lower for Saanen. Mucha et al. (2018) also reported average validation accuracies (Pearson correlation coefficients estimated between de-regressed proofs and single-step GEBV) for MY, PY, and FY (0.50 to 0.56$)$ in a UK composite dairy goat population.

It is worth noting that there were several limitations to the validation designs used in this research. First, the validation populations were small due to the limited number of genotyped individuals. Second, there was no gap in birth years between training and valida-

Table 4. Validation accuracy \pm SD of genomic (GEBV) and pedigree-based (EBV) estimated breeding values estimated for all traits using either single- or multiple-breed training populations and alternative validation designs ${ }^{1}$

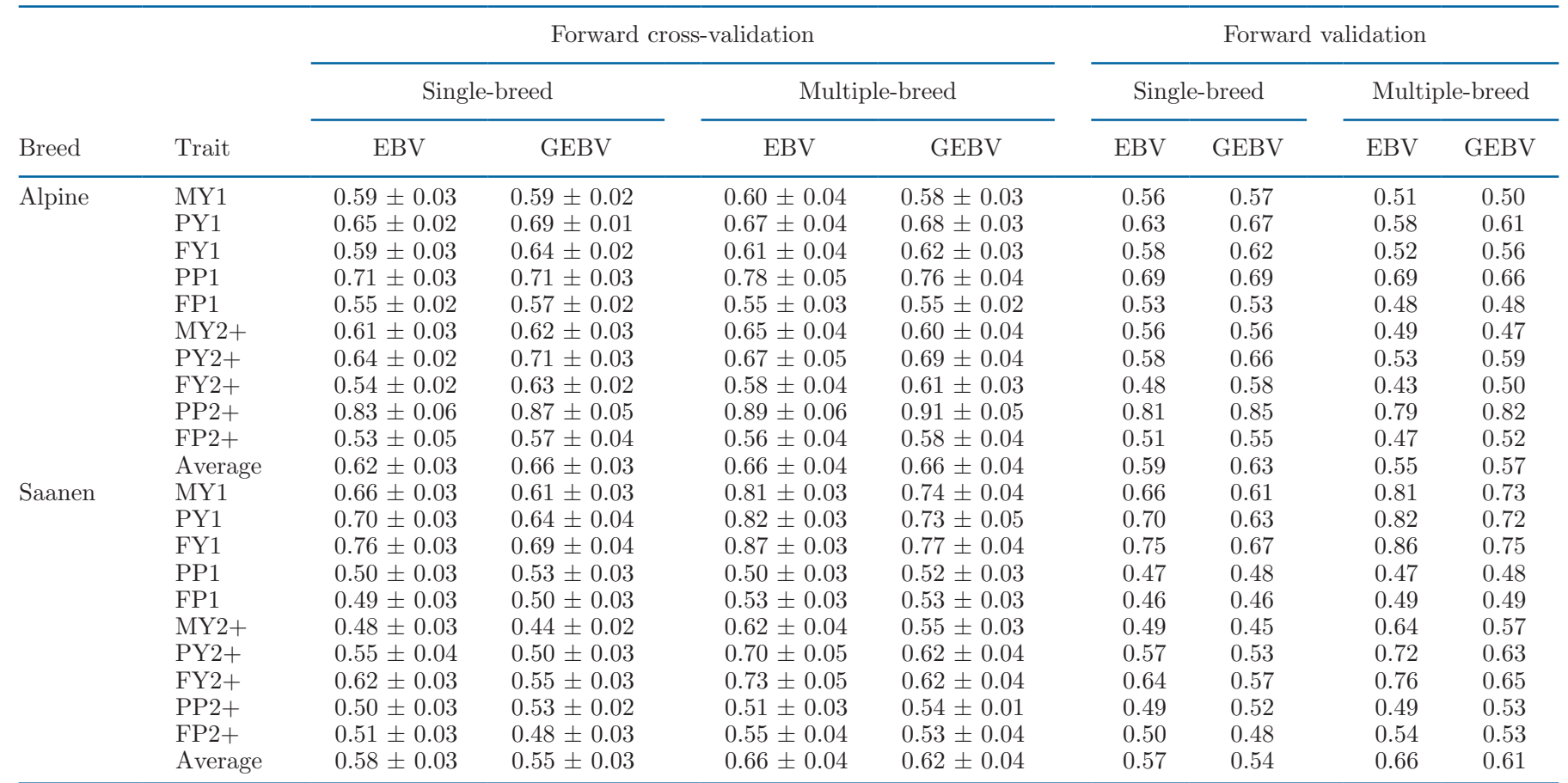

${ }^{1}$ Validation accuracies reported here for the GEBV were estimated using the optimal scaling factors for the $\mathbf{H}$ matrix (i.e., 0.95, 0.05, 1.0 and 0.8 for $\alpha, \beta, \tau$, and $\omega$, respectively). Phenotypes used in this study were full lactation records for milk yield (MY; $\mathrm{kg}$ ), protein yield (PY; $\mathrm{kg}$ ), fat yield $(\mathrm{FY} ; \mathrm{kg})$, protein percentage (PP; \%), and fat percentage (FP; \%). The codes 1 and $2+$ after the trait abbreviations refer to first and later lactations, respectively. 
tion populations, increasing the relatedness between training and validation populations (Clark et al., 2012). Third, about $90 \%$ of the genotyped animals were does. Although a minimum theoretical accuracy (EBV_full $\geq 0.50)$ was used to select validation animals, the cutoff value used was fairly low. Mucha et al. (2015) also used a validation population predominantly composed of does, but the EBV_full accuracies of validation animals were greater than 0.83 , and thus a better proxy of the animal's true breeding values. As more animals are genotyped, it will be possible to improve the validation designs used in this research, and the validation analyses should be replicated to provide a better understanding of the observed accuracy that can be expected from the implementation of genomic selection.

The average validation accuracies observed across traits in this research for GEBV_val relative to EBV_val were similar or slightly higher for the Alpine breed, but slightly lower for Saanen, suggesting relatively limited benefit of incorporating genomic information (Table 4). The gains to validation accuracy for GEBV_val relative to EBV_val varied by trait, lactation, and breed. A previous study using multiple-step GBLUP, and a subset of the Alpine animals genotyped in this research, reported gains in validation accuracy of direct genomic values relative to EBV_full of 0.22 for MY, 0.30 for PY, and 0.20 for FY (Vermette et al., 2013). However, the authors noted that the realized gains observed may have been overestimated due to the small validation population (50 animals) and the fact that the GEBV prediction equation was developed using EBV_full rather than EBV_val; however, in practice, young selection candidates would not have phenotypes contributing to their EBV. Gains to validation accuracy of GEBV relative to EBV have been previously demonstrated in validation analyses for milk production traits in dairy goat populations by Mucha et al. (2015), Carillier et al. (2013), and Teissier et al. (2018). It is also worth noting that genomic selection is generally most advantageous in lowly-heritable traits that are difficult or expensive to measure; thus, gains relative to EBV may be more pronounced in this population when other traits are considered (e.g., reproduction, disease resistance). Furthermore, the use of methods that account for regions or genes with a known major effect (i.e., $\alpha_{\mathrm{S1}^{-}} \mathrm{CN}$ ) have been successful at increasing the validation accuracy of milk production traits for French dairy goats (CarillierJacquin et al., 2016; Teissier et al., 2018, 2019), and will be explored for the Canadian population.

Validation Bias. The average validation biases, presented as a deviation of the regression coefficient from 1, were found to be low across traits when using optimal scaling parameters for $\mathbf{H}$ (Table 5). In the forward cross-validation scenarios, the average absolute biases across traits were less than 0.07 (Table 5), regardless of breed or analysis type used, and were similar between GEBV_val and EBV_val. Bias estimates were similar for the forward validation approach, ranging from -0.07 to 0.11 across traits (Table 5). Mucha et al. (2015) similarly reported a regression coefficient of 0.99 for MY using ssGBLUP, but their results were above 1 for parent averages (1.08) and EBV from pedigreebased BLUP (1.27). In contrast, Carillier et al. (2014) reported substantially lower regression coefficients ranging from 0.43 to 0.95 for ssGBLUP for MY, PY, FY, PP, and FP. The results of the present research suggest that inflation or deflation of GEBV_val are not of great concern in the Canadian dairy goat populations when optimal scaling parameters are used.

Single vs. Multiple-Breed Analyses. The differences observed in both average accuracies and biases between the single and multiple-breed analyses were minimal (Tables 4 and 5), but the trait-specific results were variable. There was a small benefit to the use of multiple-breed training populations for Saanen, possibly due to the fact that there were fewer phenotypic records available for this breed. Pooling breeds can be one strategy to increase the size of genomic training populations, which is a factor known to contribute to the accuracy of GEBV (Brito et al., 2017a), but minimal benefit from pooling the Canadian Alpine and Saanen breeds was observed in this study. This follows the conclusions of Brito et al. (2015), who suggested that the consistency of gametic phase between these breeds in the Canadian population was not high enough to encourage pooling of the training populations. On the other hand, multiple-breed analyses may be preferred for ease of implementation, and these results suggest that this is likely to make little difference in the accuracy or bias of GEBV. Carillier et al. (2014) also observed similar average validation accuracies between single-breed and multiple-breed analyses. Numerous strategies have been considered for multiple-breed genomic prediction in the literature, but improvements to validation accuracy are often minimal over single-breed analyses (Steyn et al., 2019). In this study, we used a simple approach of combining the validation populations between the 2 breeds. An alternative approach would be to treat the phenotypes for the 2 breeds as separate but genetically correlated traits. This strategy was evaluated for French Alpine and Saanen goats by Carillier et al. (2014), but it consistently resulted in lower validation accuracies than a single-trait multiplebreed approach, and thus was not considered in the present study.

Forward vs. Forward Cross-Validation. In this study, 2 different approaches for defining the validation population were compared. The widely used forward 
Table 5. Validation bias (i.e., linear regression coefficient minus 1) \pm SD of genomic (GEBV) and pedigree-based (EBV) estimated breeding values estimated for all traits using either single- or multiple-breed training populations and alternative validation designs ${ }^{1}$

\begin{tabular}{|c|c|c|c|c|c|c|c|c|c|}
\hline \multirow{2}{*}{ Breed } & \multirow{2}{*}{ Trait } & \multicolumn{4}{|c|}{ Forward cross-validation } & \multicolumn{4}{|c|}{ Forward validation } \\
\hline & & \multicolumn{2}{|c|}{ Single-breed } & \multicolumn{2}{|c|}{ Multiple-breed } & \multicolumn{2}{|c|}{ Single-breed } & \multicolumn{2}{|c|}{ Multiple-breed } \\
\hline \multirow[t]{9}{*}{ Alpine } & MY1 & $-0.06 \pm 0.07$ & $-0.04 \pm 0.05$ & $-0.04 \pm 0.03$ & $-0.03 \pm 0.03$ & -0.08 & -0.06 & -0.07 & -0.06 \\
\hline & PY1 & $-0.04 \pm 0.05$ & $-0.02 \pm 0.04$ & $-0.05 \pm 0.03$ & $-0.05 \pm 0.03$ & -0.05 & -0.01 & -0.03 & 0.01 \\
\hline & FY1 & $0.01 \pm 0.06$ & $0.04 \pm 0.05$ & $-0.02 \pm 0.04$ & $0.00 \pm 0.03$ & 0.02 & 0.05 & 0.06 & 0.09 \\
\hline & MY2+ & $0.11 \pm 0.07$ & $0.13 \pm 0.09$ & $0.06 \pm 0.02$ & $0.08 \pm 0.03$ & 0.15 & 0.21 & 0.17 & 0.20 \\
\hline & PY2+ & $0.08 \pm 0.07$ & $0.08 \pm 0.08$ & $0.06 \pm 0.02$ & $0.06 \pm 0.03$ & 0.12 & 0.15 & 0.12 & 0.14 \\
\hline & FY2+ & $0.08 \pm 0.06$ & $0.10 \pm 0.07$ & $0.05 \pm 0.03$ & $0.07 \pm 0.03$ & 0.12 & 0.18 & 0.14 & 0.17 \\
\hline & $\mathrm{PP} 2+$ & $0.04 \pm 0.03$ & $0.06 \pm 0.03$ & $0.01 \pm 0.03$ & $0.01 \pm 0.02$ & 0.04 & 0.04 & 0.06 & 0.06 \\
\hline & FP2+ & $0.06 \pm 0.08$ & $0.06 \pm 0.08$ & $0.07 \pm 0.06$ & $0.06 \pm 0.05$ & 0.05 & 0.05 & 0.06 & 0.06 \\
\hline & Average & $0.06 \pm 0.06$ & $0.07 \pm 0.06$ & $0.03 \pm 0.04$ & $0.04 \pm 0.03$ & 0.08 & 0.11 & 0.10 & 0.11 \\
\hline \multirow[t]{6}{*}{ Saanen } & MY1 & $0.00 \pm 0.05$ & $0.02 \pm 0.04$ & $0.00 \pm 0.06$ & $0.02 \pm 0.05$ & 0.01 & 0.00 & -0.01 & 0.01 \\
\hline & PY2+ & $-0.05 \pm 0.03$ & $-0.05 \pm 0.04$ & $-0.09 \pm 0.04$ & $-0.06 \pm 0.04$ & -0.12 & -0.11 & -0.16 & -0.14 \\
\hline & $\mathrm{FY} 2+$ & $-0.07 \pm 0.03$ & $-0.08 \pm 0.03$ & $-0.10 \pm 0.02$ & $-0.10 \pm 0.03$ & -0.13 & -0.12 & -0.17 & -0.16 \\
\hline & $\mathrm{PP} 2+$ & $-0.09 \pm 0.10$ & $0.01 \pm 0.08$ & $-0.10 \pm 0.11$ & $0.01 \pm 0.08$ & -0.17 & -0.06 & -0.18 & -0.05 \\
\hline & $\mathrm{FP} 2+$ & $-0.05 \pm 0.09$ & $0.00 \pm 0.09$ & $-0.06 \pm 0.10$ & $-0.01 \pm 0.10$ & -0.07 & -0.03 & -0.08 & -0.03 \\
\hline & Average & $-0.03 \pm 0.06$ & $-0.01 \pm 0.06$ & $-0.04 \pm 0.07$ & $-0.01 \pm 0.06$ & -0.06 & -0.03 & -0.07 & -0.03 \\
\hline
\end{tabular}

${ }^{1}$ Validation bias reported here for the GEBV were estimated using the optimal scaling factors for the $\mathbf{H}$ matrix (i.e., $0.95,0.05,1.0$ and 0.8 for $\alpha, \beta, \tau$, and $\omega$, respectively). Phenotypes used in this study were full lactation records for milk yield (MY; $\mathrm{kg}$ ), protein yield (PY; kg), fat yield $(\mathrm{FY} ; \mathrm{kg})$, protein percentage (PP; \%), and fat percentage (FP; \%). The codes 1 and $2+$ after the trait abbreviations refer to first and later lactations, respectively.

validation approach best represents livestock breeding practices, where older animals with records are used to predict GEBV for young animals without records. Cross-validation is another approach often used in validation analyses for populations with limited genotyping, but validation accuracies can be overestimated due to greater relationships between training and validation populations than would be observed in practice (Brito et al., 2015). Given the limited number of genotyped animals, a modified forward cross-validation approach was tested to increase the size of training populations while more closely resembling the structure of true livestock populations. In this approach, a random subset of the forward validation population was selected within each replicate, and all other animals were included in the training population to increase the number of animals in the training population. The forward crossvalidation approach increased the size of the training population by 18 to $22 \%$, depending on the breed and trait. In general, the forward cross-validation approach produced similar average validation accuracies (Table 4) and slightly lower average bias (Table 5) across traits than the forward validation approach. The lower average biases from the use of 10-fold replication is likely due to the smaller number of animals in the validation population and averaging out the effect of individual animals with GEBV_val that deviated considerably from their GEBV_full. It is worth noting that the differences between average accuracies and biases between the 2 approaches were not consistent across traits (Tables 4 and 5).

\section{Theoretical Accuracy Analyses}

Validation Population. Average theoretical accuracies for each trait, estimated using the forward cross-validation approach, for animals in the validation population are shown in Table 6 . Results for the forward validation approach are presented in Supplemental Table S2 (https://doi.org/10.7910/DVN/M2SIGF). Comparing the average theoretical accuracies between EBV and GEBV calculated from reduced and full data sets showed the amount of information gained from the inclusion of genomic information. The results observed for single and multiple-breed analyses were once again similar, with differences of less than 0.05 when averaged across traits (Table 6).

Trait-specific gains to average theoretical accuracy for GEBV_val relative to EBV_val for validation animals ranged from 17 to $44 \%$ (0.11-0.19 accuracy 
points) for Alpine and 35 to $61 \%$ (0.17-0.23 accuracy points) for Saanen, with average benefits across traits ranging from 21 to $48 \%$ (0.12-0.22), depending on the breed and analysis (Table 6 ). This result demonstrated that the GEBV had more information contributing to their prediction, and thus showed the benefit of using GEBV_val instead of EBV_val for the selection of young animals without records. Carillier et al. (2013), using multiple-step methods, reported lower average gains to theoretical accuracies of GEBV_val relative to EBV_val for validation animals than the present study, with gains as high as 0.05 for yield traits (MY, PY, FY) and 0.07 for content traits (PP, FP). Gains to theoretical accuracy of GEBV_full relative to EBV_full for Alpine validation animals averaged 9 to $12 \%$ across traits and ranged from 7 to $18 \%$ for individual traits. Similar results were observed for Saanen validation animals, with average gains across traits from 17 to $19 \%$ and gains ranging from 10 to $29 \%$ for individual traits.

Full Population. Average theoretical accuracies of EBV_full and GEBV_full across traits within each lactation for various subsets of the population (i.e., bucks vs. does and nongenotyped vs. genotyped) are presented in Table 7. Across the whole population, GEBV_full were 12 to $16 \%$ more accurate than EBV_full for genotyped animals (Table 7). Additionally, the standard deviation decreased, indicating that there was less variability in the theoretical accuracies of GEBV_full compared with EBV_full. However, there were almost no differences in the average or standard deviation of theoretical accuracies for nongenotyped animals between GEBV_full and EBV_full. Molina et al. (2018) similarly observed gains to average GEBV_full reliability of $5 \%$ when considering only genotyped animals, but only $1 \%$ across the whole population. When considering various subsets of the population in the present study, the same trend was observed (i.e., little difference was found between GEBV_full and EBV_full for nongenotyped animals). One of the benefits of ssGBLUP is the ability for genomic information to propagate through the pedigree to ancestors, which can increase the accuracy of breeding values for other animals in the population, even those that are not genotyped (Legarra et al., 2014). However, this gain in accuracy was not observed for nongenotyped animals in this population, likely due to the small number of genotyped animals relative to pedigreed animals and small number of herds that participated in genotyping. Consequently, participation in genotyping efforts should be encouraged in order for Canadian dairy goat producers to fully realize the benefits of genomic selection. Improving the genetic connectedness between herds through the use of AI or purchase of bucks from genotyped herds would also likely be of benefit.
The largest gains in theoretical accuracy for GEBV_full relative to EBV_full were observed for the groups of animals with the least amount of information contributing to their EBV prediction (Table 7), does without lactation records (35-41\%), and bucks without daughter records (46-54\%). As expected, the average accuracy gains for does with records (5-9\%) and bucks with daughter records (5-12\%) were minimal because their EBV were more accurate. The gains observed were similar between breeds and lactations (Table 7). Although the GEBV of young bucks remained lower than EBV of proven bucks (i.e., with daughter records), the use of genomic selection would still decrease the generation interval on the buck selection pathway and allow selection of replacement bucks with higher confidence at a younger age, leading to reduced rearing expenses and increased rates of genetic improvement.

\section{Future Research}

This study was the first step toward implementing genomic selection in the Canadian Dairy Goat Genetic Improvement Program, but further research is needed. For instance, different validation designs can be considered. Additionally, accounting for known major genes and regions of the genome influencing milk production traits through the use of weighted ssGBLUP (Teissier et al., 2018; 2019) or use of haplotype-based approaches (Teissier et al., 2020) may be useful to increase GEBV accuracies. Furthermore, future research should focus on additional traits that may have greater benefit from the use of genomic selection, such as conformation and SCC, as well as novel traits (e.g., lactation persistency, milk quality, reproduction, disease resistance).

\section{CONCLUSIONS}

This was the first study to perform single-step genomic predictions for milk production traits in Canadian Alpine and Saanen dairy goats. Two validation approaches (i.e., forward validation and forward crossvalidation) were tested. The forward cross-validation approach resulted in similar validation accuracies and lower bias than forward validation when averaged across traits. The use of single or multiple-breed analyses were found to have a minimal effect on the average validation accuracies and biases or average theoretical accuracies; thus, either could be considered for the implementation of genomic selection in the population. The results of this study suggested that substantial gains to selection accuracy can be expected for genotyped animals from the implementation of genomic selection across the whole population, with the largest gains being observed for does without lactation records and 


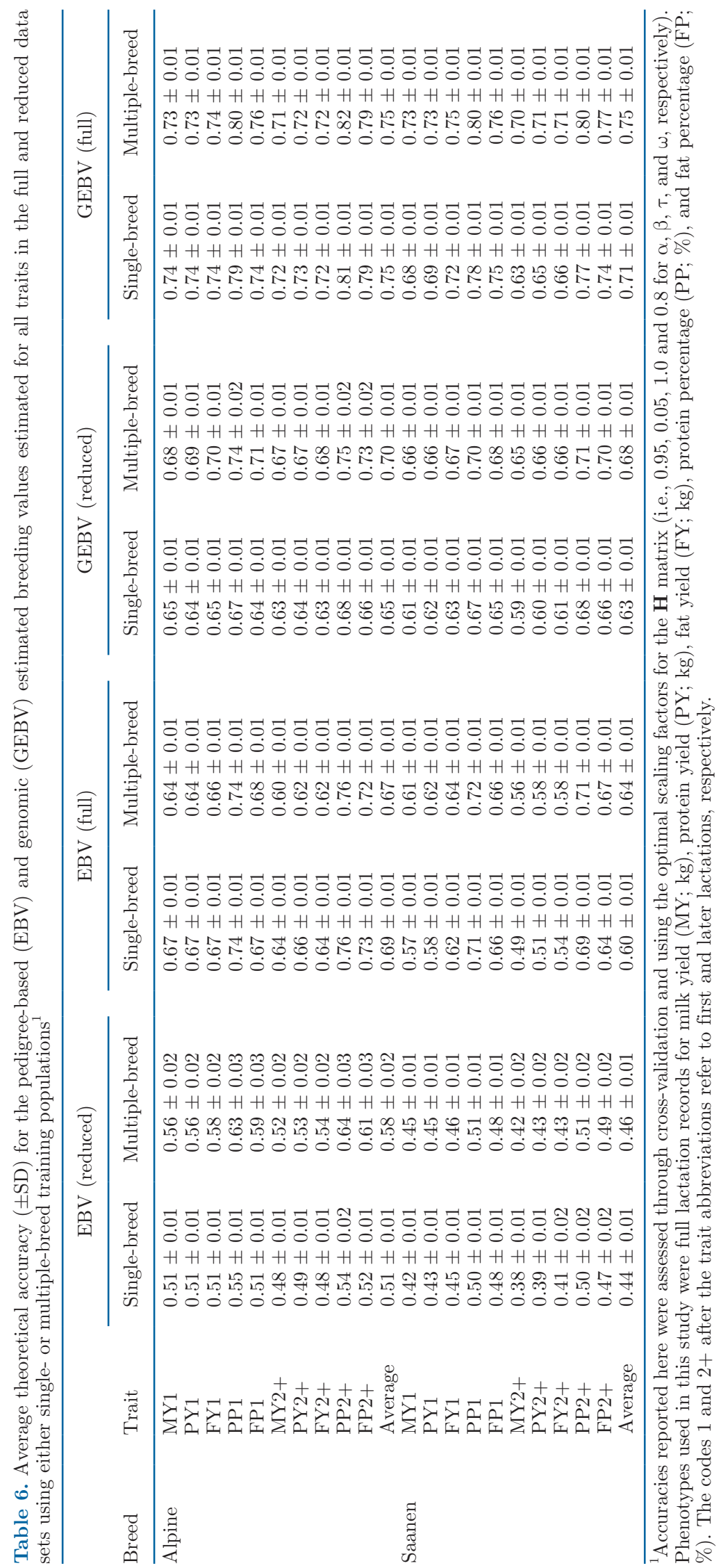


Massender et al.: GENOMIC BREEDING VALUES FOR DAIRY GOATS

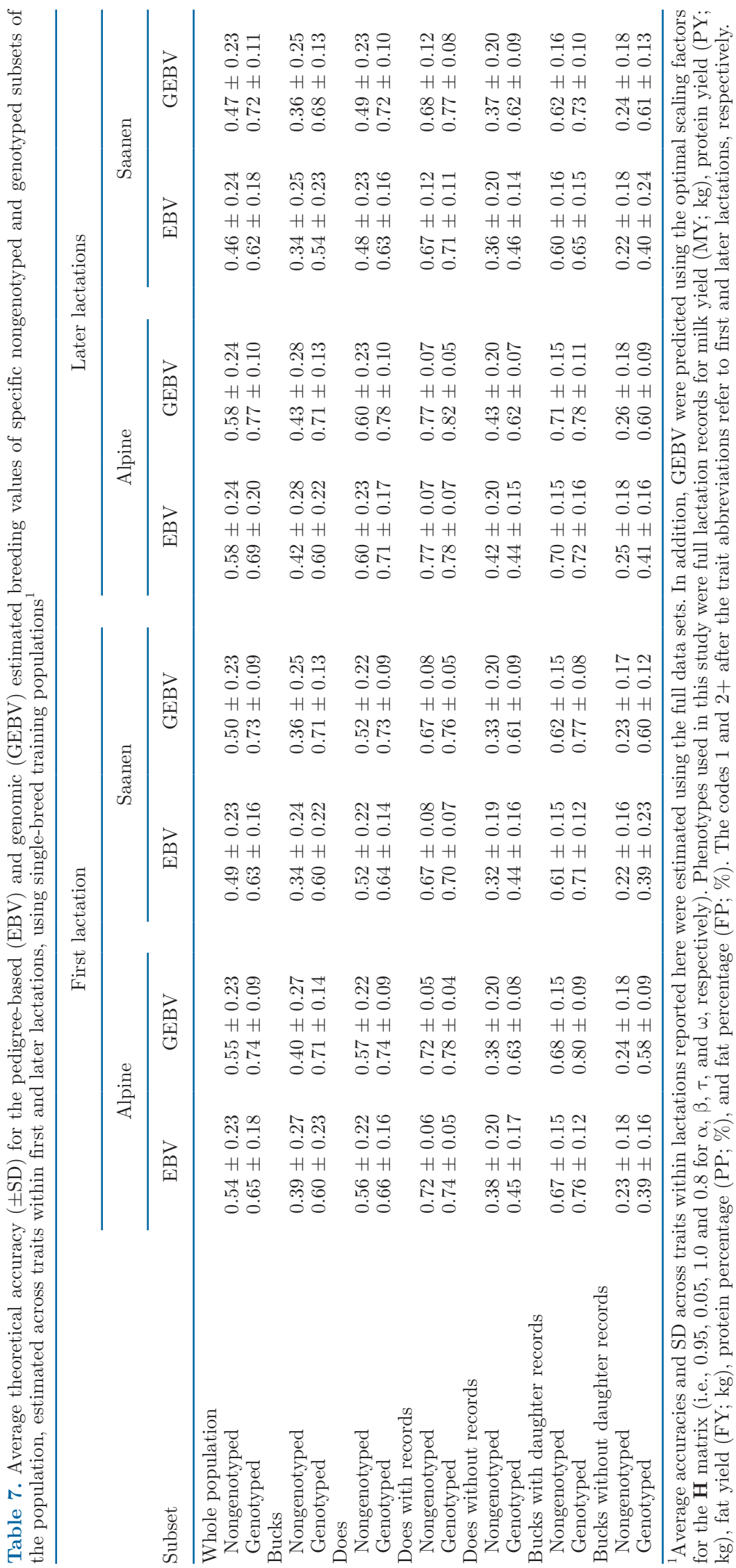


bucks without daughter records, which are usually the breeding candidates of the population. Consequently, increased selection accuracy from the implementation of genomic selection would be expected to accelerate genetic improvement for milk production traits in Canadian Alpine and Saanen goats and increase the efficiency of goat milk production in the Canadian dairy goat industry.

\section{ACKNOWLEDGMENTS}

Funding for this research was provided by the Ontario Ministry of Agriculture, Food and Rural Affairs (OMAFRA; Guelph, ON, Canada) through the Ontario Agri-Food Innovation Alliance. The first author also acknowledges the support of the Ontario Graduate Scholarship program (Toronto, ON, Canada). The authors would like to thank the many organizations and individuals in the Canadian dairy goat industry that provided data and tissue samples used in these analyses, including the Canadian Centre for Swine Improvement (Ottawa, ON, Canada), Canadian Goat Society (Guelph, ON, Canada), and Natural Resources DNA Profiling and Forensics Centre at Trent University (Peterborough, ON, Canada). This research is also part of the Small Ruminants Breeding for Efficiency and Resilience (SMARTER) project (https://www .smarterproject.eu/). A special thanks to the dairy goat producers from across Canada that supported this research by taking the time to collect tissue samples and participate in phenotype recording programs. The authors also acknowledge the Animal Breeding and Genetics Group at the University of Georgia (Athens, GA) for the use of the blupf90 family of software programs. The authors have not stated any conflicts of interest.

\section{REFERENCES}

Aguilar, I., I. Misztal, D. L. Johnson, A. Legarra, S. Tsuruta, and T. J. Lawlor. 2010. Hot topic: A unified approach to utilize phenotypic, full pedigree, and genomic information for genetic evaluation of Holstein final score. J. Dairy Sci. 93:743-752. https://doi.org/10 $.3168 /$ jds.2009-2730.

Aguilar, I., I. Misztal, S. Tsuruta, A. Legarra, and H. Wang. 2014. PREGSF90-POSTGSF90: Computational tools for the implementation of single-step genomic selection and genome-wide association with ungenotyped individuals in BLUPF90 programs. Pages 1-3 in Proc. 10th World Congr. Genet. Appl. Livest. Prod.

Beavers, L., and B. Van Doormaal. 2017. Genetic gain before and after genomics. Accessed Jan. 12, 2021. https://www.cdn.ca/images/ uploaded/file/Genetic Gain Before and After Genomics Article April 2017(3).pdf.

Bijma, P. 2012. Accuracies of estimated breeding values from ordinary genetic evaluations do not reflect the correlation between true and estimated breeding values in selected populations. J. Anim. Breed. Genet. 129:345-358. https://doi.org/10.1111/j.1439-0388 2012.00991.x.

Brito, L. F., N. Bedere, F. Douhard, H. R. Oliveira, M. Arnal, F. Peñagaricano, A. P. Schinckel, C. F. Baes, and F. Miglior. 2021.
Genetic selection of high-yielding dairy cattle toward sustainable farming systems in a rapidly changing world. Animal 15(Suppl. 1):100292. https://doi.org/10.1016/j.animal.2021.100292.

Brito, L. F., S. M. Clarke, J. C. McEwan, S. P. Miller, N. K. Pickering, W. E. Bain, K. G. Dodds, M. Sargolzaei, and F. S. Schenkel. 2017a. Prediction of genomic breeding values for growth, carcass and meat quality traits in a multi-breed sheep population using a HD SNP chip. BMC Genet. 18:7. https://doi.org/10.1186/s12863 -017-0476-8.

Brito, L. F., M. Jafarikia, D. A. Grossi, J. W. Kijas, L. R. Porto-neto, R. V. Ventura, M. Salgorzaei, and F. S. Schenkel. 2015. Characterization of linkage disequilibrium, consistency of gametic phase and admixture in Australian and Canadian goats. BMC Genet. 16:67. https://doi.org/10.1186/s12863-015-0220-1.

Brito, L. F., J. W. Kijas, R. V. Ventura, M. Sargolzaei, L. R. Porto-Neto, A. Cánovas, Z. Feng, M. Jafarikia, and F. S. Schenkel. 2017b. Genetic diversity and signatures of selection in various goat breeds revealed by genome-wide SNP markers. BMC Genomics 18:229. https://doi.org/10.1186/s12864-017-3610-0.

Canadian Dairy Information Centre. 2019. Cheese imports into Canada by variety. Accessed Jan. 12, 2021. https://aimis-simia-cdic-ccil agr.gc.ca/rp/index-eng. $\mathrm{cfm}$ ?action $=\mathrm{pR} \& \mathrm{r}=147 \& \mathrm{pdctc}=$.

Carillier, C., H. Larroque, I. Palhière, V. Clément, R. Rupp, and C. Robert-Granié. 2013. A first step toward genomic selection in the multi-breed French dairy goat population. J. Dairy Sci. 96:72947305. https://doi.org/10.3168/jds.2013-6789.

Carillier, C., H. Larroque, and C. Robert-Granié. 2014. Comparison of joint versus purebred genomic evaluation in the French multibreed dairy goat population. Genet. Sel. Evol. 46:67. https://doi .org/10.1186/s12711-014-0067-3.

Carillier-Jacquin, C., H. Larroque, and C. Robert-Granié. 2016. Including alpha s1 casein gene information in genomic evaluations of French dairy goats. Genet. Sel. Evol. 48:54. https://doi.org/10 $.1186 / \mathrm{s} 12711-016-0233-\mathrm{x}$.

Chesnais, J. P., T. A. Cooper, G. R. Wiggans, M. Sargolzaei, J. E. Pryce, and F. Miglior. 2016. Using genomics to enhance selection of novel traits in North American dairy cattle. J. Dairy Sci. 99:2413-2427. https://doi.org/10.3168/jds.2015-9970.

Christensen, O. F., and M. S. Lund. 2010. Genomic prediction when some animals are not genotyped. Genet. Sel. Evol. 42:2. https:// doi.org/10.1186/1297-9686-42-2.

Clark, S. A., J. M. Hickey, H. D. Daetwyler, and J. H. J. van der Werf. 2012. The importance of information on relatives for the prediction of genomic breeding values and the implications for the makeup of reference data sets in livestock breeding schemes. Genet. Sel. Evol. 44:4. https://doi.org/10.1186/1297-9686-44-4.

Coster, A. 2013. Pedigree: pedigree functions. Accessed Aug. 1, 2021. https://cran.r-project.org/web/packages/pedigree/pedigree.pdf.

Daetwyler, H. D., A. A. Swan, J. H. van der Werf, and B. J. Hayes. 2012. Accuracy of pedigree and genomic predictions of carcass and novel meat quality traits in multi-breed sheep data assessed by cross-validation. Genet. Sel. Evol. 44:33. https://doi.org/10.1186/ 1297-9686-44-33.

García-Ruiz, A., J. B. Cole, P. M. VanRaden, G. R. Wiggans, F. J. Ruiz-López, and C. P. Van Tassell. 2016. Changes in genetic selection differentials and generation intervals in US Holstein dairy cattle as a result of genomic selection. Proc. Natl. Acad. Sci. USA 113:E3995-E4004. https://doi.org/10.1073/pnas.1519061113.

Georges, M., C. Charlier, and B. Hayes. 2019. Harnessing genomic information for livestock improvement. Nat. Rev. Genet. 20:135-156. https://doi.org/10.1038/s41576-018-0082-2.

Goddard, M. E. 2012. Uses of genomics in livestock agriculture. Anim. Prod. Sci. 52:73-77. https://doi.org/10.1071/AN11180.

Hayes, B. J., P. J. Bowman, A. J. Chamberlain, and M. E. Goddard. 2009. Invited review: Genomic selection in dairy cattle: Progress and challenges. J. Dairy Sci. 92:433-443. https://doi.org/10.3168/ jds.2008-1646.

Legarra, A., I. Aguilar, and I. Misztal. 2009. A relationship matrix including full pedigree and genomic information. J. Dairy Sci. 92:4656-4663. https://doi.org/10.3168/jds.2009-2061. 
Legarra, A., O. F. Christensen, I. Aguilar, and I. Misztal. 2014. Single step, a general approach for genomic selection. Livest. Sci. 166:5465. https://doi.org/10.1016/j.livsci.2014.04.029.

Legarra, A., and A. Reverter. 2018. Semi-parametric estimates of population accuracy and bias of predictions of breeding values and future phenotypes using the LR method. Genet. Sel. Evol. 50:53. https://doi.org/10.1186/s12711-018-0426-6.

Lourenco, D., A. Legarra, S. Tsuruta, Y. Masuda, I. Aguilar, and I. Misztal. 2020. Single-step genomic evaluations from theory to practice: Using SNP chips and sequence data in BLUPF90. Genes (Basel) 11:790. https://doi.org/10.3390/genes11070790.

Miglior, F., A. Fleming, F. Malchiodi, L. F. Brito, P. Martin, and C. F. Baes. 2017. A 100-Year Review: Identification and genetic selection of economically important traits in dairy cattle. J. Dairy Sci. 100:10251-10271. https://doi.org/10.3168/jds.2017-12968.

Misztal, I., A. Legarra, and I. Aguilar. 2009. Computing procedures for genetic evaluation including phenotypic, full pedigree, and genomic information. J. Dairy Sci. 92:4648-4655. https://doi.org/10 $.3168 /$ jds.2009-2064.

Misztal, I., S. Tsuruta, D. A. L. Lourenco, I. Aguilar, A. Legarra, and Z. Vitezica. 2014. Manual for BLUPF90 family of programs. Accessed Jan, 12, 2021. http://nce.ads.uga.edu/wiki/lib/exe/fetch .php?media=blupf90_all2.pdf.

Misztal, I., S. Tsuruta, T. Strabel, B. Auvray, T. Druet, and D. H. Lee. 2002. BLUPF90 and related programs (BGF90). Pages 743-745 in Proc. 7th World Congr. Genet. Appl. Livest. Prod.

Molina, A., E. Muñoz, C. Díaz, A. Menéndez-buxadera, M. Ramón, M. Sánchez, M. J. Carabaño, and J. M. Serradilla. 2018. Goat genomic selection: Impact of the integration of genomic information in the genetic evaluations of the Spanish Florida goats. Small Rumin. Res. 163:72-75. https://doi.org/10.1016/j.smallrumres.2017 .12 .010 .

Mucha, S., S. Desire, L. Geddes, R. Mrode, M. Coffey, and J. Conington. 2018. Implementation of genomic selection in UK dairy goats. Pages 1-5 in Proc. 11th World Congr. Genet. Appl. Livest. Prod.

Mucha, S., R. Mrode, M. Coffey, and J. Conington. 2014. Estimation of genetic parameters for milk yield across lactations in mixedbreed dairy goats. J. Dairy Sci. 97:2455-2461. https://doi.org/10 $.3168 /$ jds.2013-7319.

Mucha, S., R. Mrode, I. MacLaren-Lee, M. Coffey, and J. Conington. 2015. Estimation of genomic breeding values for milk yield in UK dairy goats. J. Dairy Sci. 98:8201-8208. https://doi.org/10.3168/ jds.2015-9682.

Oliveira, H. R., D. A. L. Lourenco, Y. Masuda, I. Misztal, S. Tsuruta, J. Jamrozik, L. F. Brito, F. F. Silva, and F. S. Schenkel. 2019 Application of single-step genomic evaluation using multiple-trait random regression test-day models in dairy cattle. J. Dairy Sci. 102:2365-2377. https://doi.org/10.3168/jds.2018-15466.

Rupp, R., S. Mucha, H. Larroque, J. McEwan, and J. Conington. 2016. Genomic application in sheep and goat breeding. Anim. Front. 6:39-44. https://doi.org/10.2527/af.2016-0006.

Schaeffer, L. R. 2006. Strategy for applying genome-wide selection in dairy cattle. J. Anim. Breed. Genet. 123:218-223. https://doi.org/ 10.1111/j.1439-0388.2006.00595.x.

Shumbusho, F., J. Raoul, J. M. Astruc, I. Palhiere, and J. M. Elsen. 2013. Potential benefits of genomic selection on genetic gain of small ruminant breeding programs. J. Anim. Sci. 91:3644-3657. https://doi.org/10.2527/jas.2012-6205.

Shumbusho, F., J. Raoul, J. M. Astruc, I. Palhiere, S. Lemarié, A. Fugeray-Scarbel, and J. M. Elsen. 2016. Economic evaluation of genomic selection in small ruminants: A sheep meat breeding program. Animal 10:1033-1041. https://doi.org/10.1017/ S1751731115002049.

Statistics Canada. 2020. Table 32-10-0155-01 Selected livestock and poultry, historical data. Accessed Jan 12, 2021. https://www150 .statcan.gc.ca/t1/tbl1/en/tv.action?pid=3210015501.

Steyn, Y., D. A. L. Lourenco, and I. Misztal. 2019. Genomic predictions in purebreds with a multibreed genomic relationship matrix. J. Anim. Sci. 97:4418-4427. https://doi.org/10.1093/jas/skz296.
Sullivan, B. P. 2000. Genetic evaluation of Canadian dairy goats. Ottawa. Accessed Jan 12, 2021. http://www.ccsi.ca/goats/7icg/cdn -text.htm.

Teissier, M., H. Larroque, L. F. Brito, R. Rupp, F. S. Schenkel, and C. Robert-Granié. 2020. Genomic predictions based on haplotypes fitted as pseudo-SNP for milk production and udder type traits and SCS in French dairy goats. J. Dairy Sci. 103:11559-11573. https://doi.org/10.3168/jds.2020-18662.

Teissier, M., H. Larroque, and C. Robert-granié. 2019. Accuracy of genomic evaluation with weighted single-step genomic best linear unbiased prediction for milk production traits, udder type traits, and somatic cell scores in French dairy goats. J. Dairy Sci. 102:3142-3154. https://doi.org/10.3168/jds.2018-15650.

Teissier, M., H. Larroque, and C. Robert Granié. 2018. Weighted single-step genomic BLUP improves accuracy of genomic breeding values for protein content in French dairy goats: A quantitative trait influenced by a major gene. Genet. Sel. Evol. 50:31. https:// doi.org/10.1186/s12711-018-0400-3.

Tosser-Klopp, G., P. Bardou, O. Bouchez, C. Cabau, R. Crooijmans, Y. Dong, C. Donnadieu-Tonon, A. Eggen, H. C. M. Heuven, S. Jamli, A. J. Jiken, C. Klopp, C. T. Lawley, J. McEwan, P. Martin, C. R. Moreno, P. Mulsant, I. Nabihoudine, E. Pailhoux, I. Palhière, R. Rupp, J. Sarry, B. L. Sayre, A. Tircazes, J. Wang, W. Wang, and W. Zhang.International Goat Genome Consortium. 2014. Design and characterization of a 52K SNP chip for goats. PLoS One 9:e86227. https://doi.org/10.1371/journal.pone.0086227.

Tsuruta, S., D. A. L. Lourenco, Y. Masuda, I. Misztal, and T. J. Lawlor. 2019. Controlling bias in genomic breeding values for young genotyped bulls. J. Dairy Sci. 102:9956-9970. https://doi.org/10 .3168/jds.2019-16789.

van der Werf, J. H. J. 2009. Potential benefit of genomic selection in sheep. Proc. Assoc. Adv. Anim. Breed. Genet. 18:38-41.

Van Eenennaam, A. L., K. A. Weigel, A. E. Young, M. A. Cleveland, and J. C. M. Dekkers. 2014. Applied animal genomics: results from the field. Annu. Rev. Anim. Biosci. 2:105-139. https://doi.org/10 .1146/annurev-animal-022513-114119.

Van Vleck, L. D. 1993. Variance of prediction error with mixed model equations when relationships are ignored. Theor. Appl. Genet. 85:545-549. https://doi.org/10.1007/BF00220912.

VanRaden, P. M. 2008. Efficient methods to compute genomic predictions. J. Dairy Sci. 91:4414-4423. https://doi.org/10.3168/jds .2007-0980.

Vermette, S., M. Jafarikia, L. Maignel, S. Wyss, B. Sullivan, L. Brito, F. Schenkel, K. Weaver, and S. Girouard. 2013. Goat herd improvement on productivity and health using genomics. Accessed Jan 12, 2021. https://www.researchgate.net/publication/303311547 _Goat_Herd_improvement_on_productivity_and_health_using genomics.

Wickham, M., J. Averick, W. Bryan, L. Chang, R. McGowan, G. François, A. Grolemund, L. Hayes, J. Henry, M. Hester, T. Kuhn, E. Pedersen, S. Miller, K. Bache, J. Müller, D. Ooms, D. Robinson, V. Seidel, K. Spinu, D. Takahashi, C. Vaughan, K. Wilke, Woo, and H. Yutani. 2019. Welcome to the tidyverse. J. Open Source Softw. 4:1686. https://doi.org/10.21105/joss.01686.

\section{ORCIDS}

Erin Massender (1) https://orcid.org/0000-0002-3008-8168 Luiz F. Brito (ํ) https://orcid.org/0000-0002-5819-0922 Laurence Maignel $\odot$ https://orcid.org/0000-0001-8010-6312 Hinayah R. Oliveira @ https://orcid.org/0000-0002-0355-8902 Mohsen Jafarikia @ https://orcid.org/0000-0002-7911-5008 Christine F. Baes ๑ https://orcid.org/0000-0001-6614-8890 Brian Sullivan @ https://orcid.org/0000-0002-7593-0865 Flavio S. Schenkel ๑ https://orcid.org/0000-0001-8700-0633 